\title{
A general model for the life cycle of Dolichopoda cave crickets (Orthoptera: Rhaphidophoridae)
}

\author{
CAmilla BERNARDiNI and Claudio DI RUSSO \\ c/o Dipartimento di Biologia Animale e dell’Uomo, Università degli Studi di Roma La Sapienza \\ Viale dell’Università 32, 00185 Rome, Italy; email: beagle.amb@inwind.it
}

Key words. Life cycle, model, RAMAS/stage, Dolichopoda, cave crickets

\begin{abstract}
A general model of the Dolichopoda cave cricket life cycle was produced using RAMAS/stage simulations based on the Beverton \& Holt recruitment function. The model indicates the main population parameters responsible for life cycle adjustments to ecologically different cave habitats. The lack of a uniform rate of oviposition throughout adult life, combined with egg and nymphal diapause, results in regular population growth characterized by adults emerging every two years and cohorts overlapping every other year. This pattern is common in populations living in artificial caves where the scarcity of food is likely to favour individuals that synchronise their activity with the seasonal variations in the epigean habitat. In contrast, a uniform rate of oviposition throughout adult life and no egg or nymphal diapause results in a continuous reproductive activity, and the occurrence of adults all the year round. In this case, it was not possible to distinguish between cohorts. This pattern is well represented in populations inhabiting natural caves with stable food resources. The availability of data for a population that resulted from an experimental colonization allowed us to test this model.
\end{abstract}

\section{INTRODUCTION}

In the last few years, several studies on Dolichopoda population biology have provided a deeper knowledge of the ecology of these cave crickets (Carchini et al., 1983, 1991; Di Russo et al., 1994; De Pasquale et al., 1995). In particular, these studies have provided the experimental background that resulted in the development of hypotheses on the evolution of alternative life history tactics in populations subject to different environmental pressures.

Dolichopoda Bolivar is a genus of Rhaphidophoridae widely distributed in the Mediterranean area, with about 30 species from the Pyrenees to the Caucasus (Baccetti, 1982).

The life cycle of Dolichopoda is typically semivoltine (one generation per two years), with at least 9 postembryonic instars before the adult stage (Boudou-Saltet, 1971; Di Russo et al., 1987).

Dolichopoda cave crickets inhabit both natural and man made caves (i.e. artificial hypogean habitats, cellars, Roman aqueducts etc.). These two habitats are strongly different in their ecological parameters. Natural caves are commonly described as stable habitats as far as climate, resource availability and community structure are concerned (Culver, 1982). In the contrast, artificial caves appear to be strongly affected by seasonality in climatic conditions and trophic resources. Therefore, populations living in these two habitats differ in their phenology and life history traits (Di Russo et al., 1994).

In particular, populations inhabiting natural caves are characterized by a constant aseasonal age structure, absence of nymphal diapause and eggs hatching all the year round. In contrast, the life cycle of crickets in artificial caves is characterized by strong seasonality in repro- duction, nymphal growth and age structure (Carchini et al., 1991; Di Russo et al., 1994).

Modelling these patterns by varying a few parameters is a useful tool for investigating life cycle variations in natural populations.

Moreover, when demographic data (i.e. population size, age structure, mortality rate), on experimental or natural colonizations of cave habitats are available, this approach gives the possibility to compare the model's predictions with the present status of the populations.

In this paper, we report a simple model of Dolichopoda life cycle based on a Leslie matrix approach (Leslie, 1945) performed by RAMAS/stage simulation (Ferson, 1991). Such an approach is particularly appropriate for insects with age-structured populations. A model of the life cycle of these cave crickets was used to study the main parameters involved in the adjustment of their life phases to the ecologically different environment of the caves. The model was tested using data from a population that resulted from an experimental colonization event.

\section{MATERIALS AND METHODS}

The life cycle graph (Caswell, 2001) used here was constructed based on D. geniculata Costa life cycle (Di Russo et al., 1987; Sbordoni et al., 1987). The life cycle graph includes four age classes: Eggs, Young Nymphs (YNYMPHS), Old Nymphs (ONYMPHS) and Adults (Fig. 1). Furthermore each age class is divided into two stages of 3 months according to its duration and that of the life cycle of $D$. geniculata. Finally, observations on a population of $D$. linderi Dufour, which originated from an experimental transplantation carried out in France by researchers of the Laboratoire Souterrain of CNRS in 1978, were used to test the model. In this experiment 15 adult individuals with an approximately 1:1 sex ratio, were transplanted from Valmanya cave, located in Mount Canigou (Eastern Pyrenees), to Bonrepaux cave in Ariege (Di Russo, 1993). The 


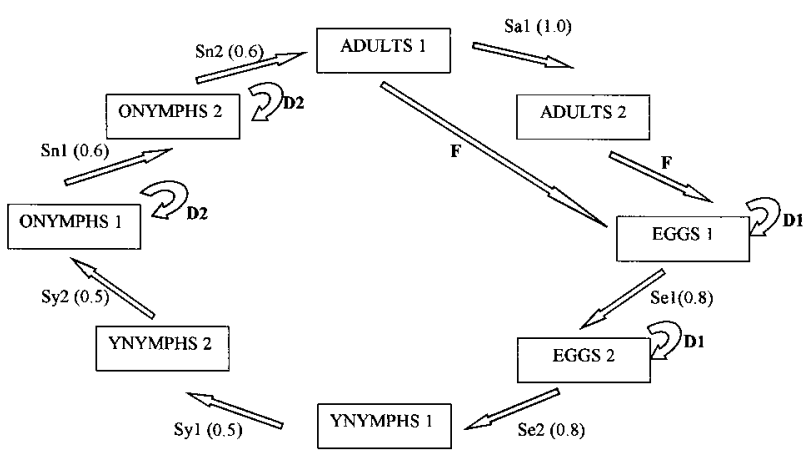

Fig. 1. Life cycle used in the model. The symbols YNYMPHS and ONYMPHS indicate Young Nymphs and Old Nymphs respectively. The codes F and D1 and D2 represent fecundity, egg and nymphal diapause respectively. Bent arrow represents no recruitment due to egg and nymphal diapause. The codes Sa, Se, Sy and Sn indicate the survival rates used in the transitions.

recipient natural cave was not occupied by Dolichopoda cave crickets.

\section{Estimation of parameters and model}

RAMAS/stage modelling consists of creating "stages”, which are the state variables, and equations that determine how they change through the time. The equations used are based on replacement functions, where transitions to and from other stages are regulated by biological and environmental parameters.

In our model, the fecundity obtained by rearing 15 couples from 7 D. geniculata populations was $45 \pm 19$ eggs per female. Survival rate was obtained in two ways. For the embryonic stage the percentage that hatched in the breeding experiments was used. For the remaining age classes, indirect estimates derived from the decrease in relative abundance from one age group to the next, as reported in Krebs (1985) was used. In this case the abundances were estimated from monthly samples of a large number of individuals from all age classes in the population. For each age group the decline was calculated using the following equation:

$$
\mathrm{S}=\mathrm{a}\left(\mathrm{x}_{\mathrm{t}}\right) / \mathrm{a}\left((\mathrm{x}-1)_{(\mathrm{t}-1)}\right)
$$

where $S$ is the survival rate, the numerator is the relative abundance of age $\mathrm{x}$ at time $\mathrm{t}$ and the denominator is the relative abundance of age $\mathrm{x}-1$ at time $\mathrm{t}-1$

These values are indicated in the transition labels on Fig. 1. The duration of each transition is three months. All populations were assumed to have a 1:1 sex ratio, as observed in several Dolichopoda populations (Carchini et al., 1983).
For all the simulations, each run for over 200 steps (50 years) and repeated 1000 times, a recruitment derived from the Beverton \& Holt function (Beverton \& Holt, 1957) was used:

$$
\mathrm{N}(\mathrm{x}+1)_{(\mathrm{t}+1)}=\mathrm{N}\left(\mathrm{x}_{\mathrm{t}}\right) /\left(1 / \mathrm{h}\left(\mathrm{x}_{\mathrm{t}}\right)+\mathrm{N}\left(\mathrm{x}_{\mathrm{t}}\right) / \mathrm{K}\right) \text {, }
$$

where $N\left(x_{t}\right)$ and $N(x+1)_{(t+1)}$ are the number of individuals of age class $x$ and $x+1$ occurring at time $t$ and $t+1$, respectively, $\mathrm{h}(\mathrm{x})$ the survival rate of age class $\mathrm{x}$ and $\mathrm{K}$ is the carrying capacity of the population. This function is similar to that introduced by Leslie (1957) as a discrete version of the logistic model.

Several factors determined the choice of this densitydependent function. First, this type of equation can be used to model population growth in semelparous species. In this case the time unit has a precise biological meaning: the time between two periods of reproduction. On the other hand, the restricted habitat and intraspecific competition for the limited food available in caves can affect population growth. Furthermore, most of the populations studied by mark-recapture over long periods, remained stable in size. The smallest population recorded had a size of 213 (s.d. +/ 166) individuals and the largest 10900 (s.d. +/- 4400) individuals (Carchini et al., 1983). The maximum value recorded was used as the carrying capacity $(\mathrm{K})$ in the Beverton \& Holt function.

To modulate the simulations different fecundity rates were arbitrarily assigned to the two adult stages (Adults1 and Adults2 in the life cycle graph) (Table 1). However, the subdivision of these values was made based on the observations on egg production in rearing experiments (Di Russo et al., 1994). In order to simulate seasonality and diapause in eggs and nymphs, a percentage of individuals accumulation and release was applied by a cyclic timer $(1,1,1,1 / 0,0,0,0)$ to egg and nymphal replacement (Table 1). The values for diapause intensity were derived from experimental data on embryonic and nymphal development (Di Russo et al., 1994). The subdivision into four steps represents the four seasons of a year. Environmental stochasticity, tested by single simulations, was introduced into the model by using random variables drawn from a normal distribution of egg production and diapause intensity, as suggested by Arçakaya (1991). All these distributions ranged between 0 and 1 .

\section{RESULTS}

\section{Life cycle model}

Using values for fecundity and survival rates derived from experimental data a general model of the Dolichopoda life cycle was constructed. In all the simulations population growth is represented by the mean number of adults ; the initial population size was no more than two.

Table 1 shows the parameters used in all simulations.

Fig. 2 shows the result of a simulation in which fecundity of Adults1 was $40 \pm 12$ eggs and of Adults $2 \pm 1$

TABLE 1. List of parameters used in the different simulations (---- not considered). F and D symbols indicate codes for fecundity,

\begin{tabular}{|c|c|c|c|c|c|c|}
\hline & \multicolumn{2}{|c|}{ Fecundity (F) } & \multicolumn{2}{|c|}{ Egg diapause (D1) } & \multicolumn{2}{|c|}{ Nymphal diapause (D2) } \\
\hline & Adults1 & Adults2 & Eggs1 & Eggs2 & ONymphs1 & ONymphs2 \\
\hline $1^{\text {st }}$ simulation & $40 \pm 12$ & $5 \pm 1$ & $0.1 \pm 0.05$ & $0.1 \pm 0.05$ & 0.99 & 0.15 \\
\hline $2^{\text {nd }}$ simulation & $22 \pm 8$ & $22 \pm 8$ & $0.1 \pm 0.05$ & $0.1 \pm 0.05$ & 0.99 & 0.15 \\
\hline $3^{\text {rd }}$ simulation & $40 \pm 17$ & $5 \pm 2$ & $0.1 \pm 0.05$ & $0.1 \pm 0.05$ & $0.99 \pm 0.02$ & $0.15 \pm 0.05$ \\
\hline $4^{\text {th }}$ simulation & $22 \pm 8$ & $22 \pm 8$ & ---- & ---- & ---- & --- \\
\hline $5^{\text {th }}$ simulation & $45 \pm 19$ & ---- & ---- & ---- & ---- & --- \\
\hline D. linderi simulation & $36 \pm 14$ & $4 \pm 1$ & $0.1 \pm 0.05$ & $0.1 \pm 0.05$ & $0.99 \pm 0.02$ & $0.15 \pm 0.05$ \\
\hline
\end{tabular}
egg and nymphal diapause used in the life cycle. 


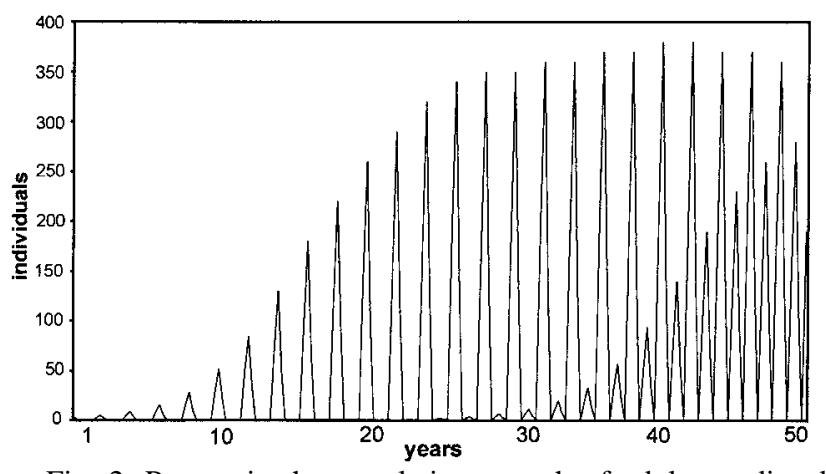

Fig. 2. Pattern in the population growth of adults predicted when the parameters reported in Table 1 were used in the $1^{\text {st }}$ simulation.

eggs. Simulation also involved diapause of $10 \% \pm 5 \%$ of the eggs, which prolonged their development by three months. A strictly regulated diapause, expressed as a delay in development in 99\% of ONYMPHS1 and 15\% of ONYMPHS2, was also considered. This resulted in the population growth showing a cyclical and regular pattern characterized initially by a slow increase and later by a stable population of about 400 individuals after 30 years. Over this time span adults occur every two years, confirming the semivoltine life cycle. Starting from the $25^{\text {th }}$ year, a second cohort, synchronously overlapping the first every other year, develops. As a result adults emerge every year.

Performing a similar simulation in which the adult stages had the same fecundity ( $2^{\text {nd }}$ simulation, Table 1$)$ does not result in different population growth patterns. On the other hand, a strong variation in population growth patterns resulted, when stochasticity was introduced in the form of a $2 \%$ and $5 \%$ variance in the normal distribution of nymphal diapause. In this case, the population is characterized by several irregular, sharp fluctuations (Fig. 3).

In a fourth simulation, reported in Fig. 4, there was no egg or nymphal diapause. Furthermore an equal number of eggs was assigned to each adult stage. In this case an initially slow, cyclical, (as in previous simulations) population growth occurs. Then, starting around the $15^{\text {th }}$ year,

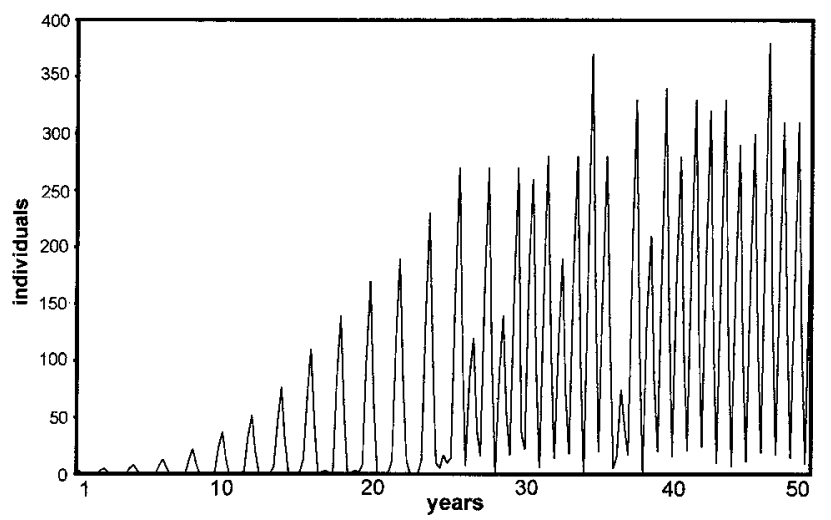

Fig. 3. Pattern in the population growth of adults predicted when the parameters reported in Table 1 were used in the $3^{\text {rd }}$ simulation.

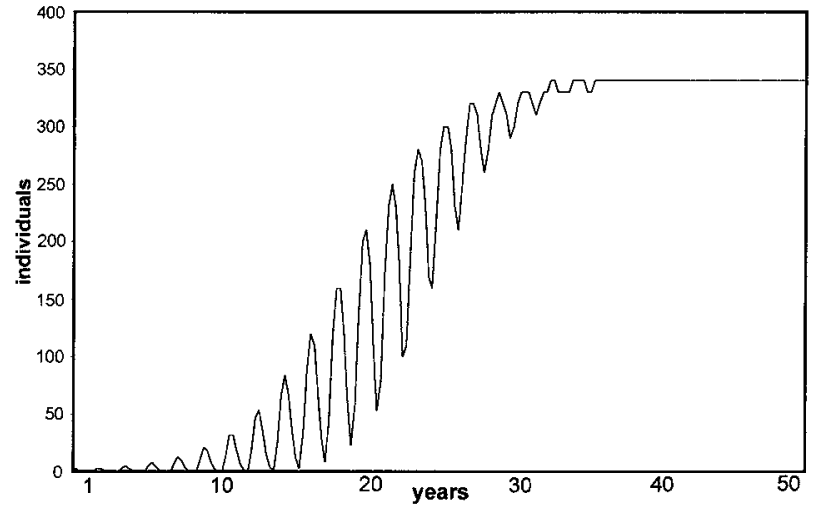

Fig. 4. Pattern in the population growth of adults predicted when the parameters reported in Table 1 were used in the $4^{\text {th }}$ simulation.

the population growth quickly increases, and it stabilizes at 350 individuals around the $30^{\text {th }}$ year. Moreover, starting from the $20^{\text {th }}$ year, because of the occurrence of adults in each period of the year, the distinction between cohorts of adults is no longer possible. Also in this simulation, stochasticity in the fecundity did not affect the population trajectory. Finally, assigning the total fecundity to the first adult stage in this simulation ( $5^{\text {th }}$ simulation, Table 1$)$ resulted in a semivoltine life cycle, the emergence of adults every two years and the lack of an overlap between cohorts (Fig. 5).

Result of the comparison of the simulation with the data obtained from the colonization experiment, is reported in Fig. 6. In this case the model parameters used were those appropriate for D. linderi (Boudou-Saltet, 1971) (see Table 1). In particular a fecundity of 40 eggs and a founder population of 8 gravid females, as described by Di Russo (1993), were used. The shape of the population trajectory seems to confirm the success of the colonization and indicates that population will stabilize at 500 individuals after 12-14 years, and cohorts in alternate years will became detectable starting from the $13^{\text {th }}$ year.

\section{DISCUSSION}

As previously reported, studies on life history variation in Dolichopoda cave crickets (Di Russo et al., 1987,

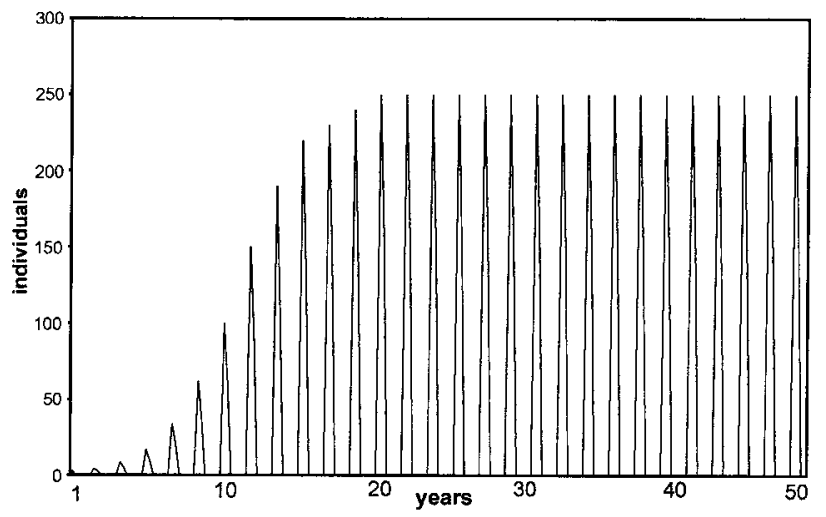

Fig. 5. Pattern in the population growth of adults predicted when the parameters reported in Table 1 were used in the $5^{\text {th }}$ simulation. 


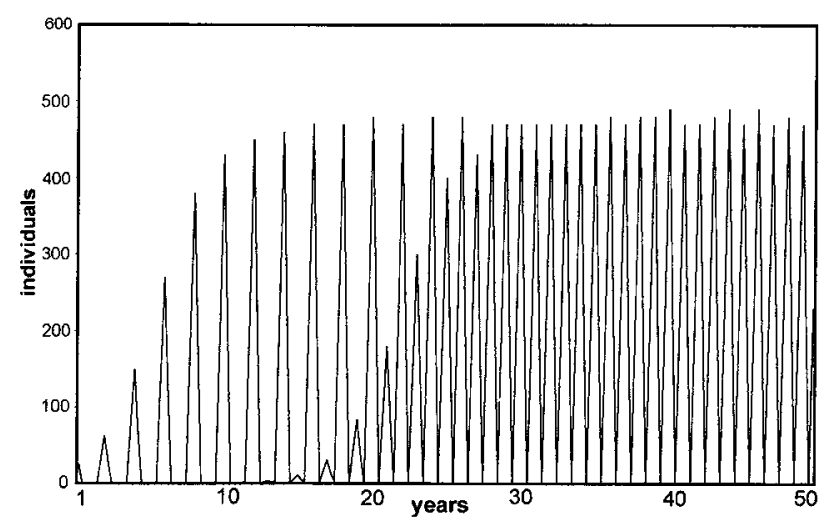

Fig. 6. Pattern in population growth of adults predicted when the data from an experimental colonization by $D$. linderi were used.

1994) allowed us to identify two main life-cycle patterns in cricket populations. That typical of populations inhabiting natural caves with stable food resources, is characterized by an aseasonal age structure, absence of nymphal diapause and eggs hatching all the year round. That common in populations living in artificial caves, shows a strong seasonality in reproduction, nymphal growth and age structure. This latter life-cycle is likely to be similar to the ancestral, heterodynamic (sensu Masaki \& Walker, 1987) and semivoltine life-cycle that probably characterized the boreal Rhaphidophoridae, which have inhabited wet forests in temperate regions since the Miocene (Hubbell \& Norton, 1978).

Several factors might account for life history variation in Dolichopoda. A seasonal life cycle is an adaptive trait that allows Dolichopoda crickets to adjust their activities to the seasonal variations in the epigean habitats from which they obtain their food. On the other hand, an aseasonal life cycle may be adaptive for crickets exploiting food such as bat guano deposits in caves. In fact, under constant environmental conditions, populations tend to reach the carrying capacity of the habitat and their increases are limited by intraspecific competition for food. In such conditions heterogeneity in size and age, associated with the aseasonal life cycle, may reduce competition (Ebenmann, 1987; Polis, 1984.).

Modelling the life cycle of Dolichopoda populations allowed us to investigate the main factors causing changes in life cycle.

The results show the fundamental role of nymphal diapause and time of oviposition in shaping the life cycle of Dolichopoda cave crickets.

The seasonal life cycle, in which adults occur every year and annual cohorts overlap, is strongly regulated by nymphal diapause, less so by egg diapause and time of oviposition. Moreover, nymphal diapause seems to be more sensitive to random variation. In fact stochastic variation in the incidence of nymphal diapause produced strong population fluctuations (Fig. 3). Considering the strong seasonal variation in temperature observed in artificial caves, ranging from $9^{\circ} \mathrm{C}$ in the winter to $18^{\circ} \mathrm{C}$ in summer (Carchini et al., 1983), it is possible to hypothe- size that temperature plays a crucial role in determining the incidence of nymphal diapause overwintering.

Comparison of Fig. 2 and Fig. 4 indicates that changes from the first type of life cycle to a completely aseasonal one seems to occur mainly as a result of no nymphal diapause combined with an equal distribution of egg production throughout adult life. In fact, in the simulation in which both adult stages produced the same number of eggs (i.e. reproduction throughout adult life) and there was no diapause, adults occurred in each period of a year and the distinction between cohorts was not possible after the $20^{\text {th }}$ years. As for the morphological traits of many troglobites (i.e. blindness and depigmentation), the loss of diapause control in the aseasonal environments is expected as a kind of regressive neutral evolution (Culver, 1982). The stable environment of natural caves, with annual temperature variation usually limited to $1^{\circ} \mathrm{C}$ or $2^{\circ} \mathrm{C}$ (Di Russo et al., 1999), is likely to favour the survival and reproduction of phenotypes with an aseasonal life-cycle. As far as the time span required, changes in life cycle patterns were observed in some epigean crickets over short periods (as short as 10 generations), as a consequence of colonization or artificial selection (Masaki \& Walker, 1987).

Therefore, the modulation of nymphal diapause combined with the synchronous laying of eggs seems to have a fundamental role in adjusting the life cycle of Dolichopoda populations to different habitat conditions.

\section{Why and how cohorts come to overlap?}

Since Dolichopoda cave crickets show a typical semivoltine life cycle a single colonization is likely to result in the lack of mobile individuals for 6-9 months, the time required for embryonic development and in the emergence of adults every two years, as in the semivoltine cycle (Fig. 5). However, this has never been recorded in Dolichopoda populations.

As previously outlined, stopping nymphal recruitment for three or six months quickly produced overlapping cohorts as usually observed in the seasonal life cycle of Dolichopoda. In this case there are two cohorts formed by individuals of different ages overlapping each other in autumn and the emergence of adults occurs every year. The recruitment of new cohorts is based on individuals that stop growing during the nymphal stage, as documented by observations on dormancy in Dolichopoda populations (Di Russo et al., 1994). The meaning of this finding is uncertain and might be related to the temporal exploitation of habitats. However, since this life cycle pattern is common in populations in artificial caves, subjected to environmental and trophic seasonality, these crickets could have retained the ancestral diapause mechanisms.

Models are considered to be structurally valid if they replicate the behaviour of a real system (Power, 1993). Therefore, the data on the experimental colonization carried out in France, could be a good test for our model. In particular we compared the present status of the transplanted population with that predicted by our model. As shown in Fig. 6, the deterministic dynamics indicate suc- 
cessful colonization and a stable population of 500 individuals after $12-14$ years. The cohorts in alternating years became detectable starting from the $13^{\text {th }}$ year. The prediction of this simulation seems to correspond to the experimental observations. In fact the estimates of population size made after 12 years, in three consecutive years (1989-1991), indicate an average of 400 individuals; over the same period the yearly alternation of cohorts was also observed.

ACKNOWLEDGEMENTS. We are grateful to Corrado Francolini (Università degli Studi di Roma, Tor Vergata, Italy) for help in the construction of the model and to Valerio Sbordoni (Università degli Studi di Roma, Tor Vergata, Italy) for financial support. We also thank Christian Juberthie (Laboratoire Souterrain of CNRS - Moulis, France), who gave us the opportunity to study experimental colonization by Dolichopoda linderi in the Eastern Pyrenees.

\section{REFERENCES}

ARÇAKAYA H.R. 1991: A method for simulating demographic stochasticity. Ecol. Model. 54: 133-136.

BACCETTI B. 1982: Ortotteri cavernicoli italiani (Notulae Orthopterologicae. XXXVI). Lav. Soc. Ital. Biogeogr. Verona. 1978 (n.s.) 6: 195-200.

Beverton R.J.H. \& Holt S.J. 1957: On the dynamics of exploited fish populations, (Great Britain). Minist. Agr., Fish. \& Food. Fish. Invest. (series 2) 19: 5-533.

Boudou-Saltet P. 1971: Observation du cycle vital, en elevage, d'une Orthoptère cavernicole Dolichopoda linderi Duf. Bull. Soc. Hist. Natur. Toulouse 107: 301-305.

Carchini G., Rampini M., Severini C. \& Sbordoni V. 1983: Population size estimates of four species of Dolichopoda in natural and artificial caves of Central Italy (Orthoptera: Rhaphidophoridae). Mem. Biospeol. 10: 341-347.

Carchini G., Di Russo C. \& Sbordoni V. 1991: Contrasting age structures in cave crickets populations: patterns and significance. Ecol. Entomol. 16: 305-314.

CAswell H. 2001: Matrix Population Models: Construction, Analysis and Interpretation. Sinauer Assoc. Publ., Sunderland, MA, 713 pp.

Culver D.C. 1982: Cave life. Evolution and Ecology. Harvard University Press, Cambridge, Mass, 189 pp.

De Pasquale L., Cesaroni D., Di Russo C. \& Sbordoni V. 1995: Trophic niche, age structure and seasonality in Dolichopoda cave crickets. Ecography 18: 217-224.
Di Russo C. 1993: Adaptations et Divergence Evolutive des Populations des Dolichopodes des Pyrenées Orientales (Groupe D. linderi). These de doctorat. Université P. Sabatier Toulouse, $70 \mathrm{pp}$.

Di Russo C., Vellei A., Carchini G. \& Sbordoni V. 1987: Life cycle and age structure of Dolichopoda populations (Orthoptera, Rhaphidophoridae) from natural and artificial cave habitats. Boll. Zool. 54: 337-340.

Di Russo C., Carchini G. \& Sbordoni V. 1994: Life-history variation in Dolichopoda cave crickets. In: Danks H.V.(ed.): Insect Life-Cycle Polymorphism. Kluwer Acad. Publ., Dordrecht, Netherlands, pp. 205-226.

Di Russo C., Carchini G., Rampini M., Lucarelli M. \& SborDONI V. 1999: Long term stability of a terrestrial cave community. Int. J. Speleol. 26, 1-2 (1997): 75-88.

EBENMAN B. 1987: Niche differences between age classes and intraspecific competition in age-structured populations. $J$. Theor. Biol. 124: 25-33.

FERSON S. 1991: RAMAS/Stage. Generalized Stage-Based Modeling for Population Dynamics. Applied Biomathematics, Setauket, New York, 107 pp.

HubBel T.H. \& Norton R.N. 1978: The systematics and biology of cave crickets of the North American tribe Hadenoecini (Orthoptera Saltatoria: Ensifera: Rhaphidophoridae: Dolichopodinae). Misc. Publ. Mus. Zool. Univ. Michigan 158: 1-124.

Krebs C. J. 1985: Ecology: The Experimental Analysis of Distribution and Abundance, $3^{\text {rd }} E d$. Harper \& Row, New York, $678 \mathrm{pp}$.

LesLIE P.H. 1945: On the use of matrices in certain population mathematics. Biometrika 33: 183-212.

LesLie P.H. 1957: An analysis of the data for some experiments carried out by Gause with populations of the Protozoa, Paramecium aurelia and Paramecium caudatum. Biometrika 44: 314--327.

Masaki S. \& Walker T.J. 1987: Cricket life cycles. In: Hecht M.K, Wallace B. \& Prance G.T. (eds): Evolutionary Biology. Plenum Press, New York, pp. 349-423.

Polis G.A. 1984: Age structure component of niche width and intraspecific resource partitioning: can age groups function as ecological species? Am. Nat. 123: 541-564.

POWER M. 1993: The predictive validation of ecological and environmental models, Ecol. Model. 68: 33-50.

Sbordoni V., Allegrucci G., Caccone A., Carchini G. \& CesaRONI D. 1987: Microevolutionary studies in Dolichopodinae cave crickets, In: Baccetti B. (ed.): Evolutionary Biology of Orthopteroid Insects. Ellis Horwood, Chichester, England, pp. 514-540.

Received October 25, 2002; revised August 11, 2003; accepted October 20, 2003 